\title{
Chronic Pain in a Biracial Cohort of Young Women
}

\author{
Octavia Plesh*, Stuart A. Gansky and Donald A. Curtis
}

Department of Preventive \& Restorative Dental Sciences, University of California, San Francisco

\begin{abstract}
This is a longitudinal study of a large US biracial community cohort of 732 young women - 50\% AfricanAmerican and 50\% Caucasian - specifically investigating incidence, remission, and progression of, as well as factors associated with common chronic pains (back, head, face, chest and abdomen). The results show back, head and abdominal pains were the most common, severe and persistent pains. Facial pain, although less common and severe, was the only pain presenting significant racial differences with Caucasians having higher prevalence, incidence and persistence; incidence per 1000 person-years was 58 for Caucasians and 18 for African-Americans while remission per 1000 personyears was 107 for Caucasians and 247 for African-Americans $(\mathrm{p}<0.05)$. Risk factors associated with incidence (I) differed from those associated with persistence $(\mathrm{P})$, perhaps due to the young age and shorter pain duration in this population. Face pain incidence, but not persistence for example, was associated with student status, fatigue, perceived stress and general health. Depression does not seem to be associated with any of these pains. However, increased number of existing pain sites was related to subsequent increase chance of developing new pain (I) or maintaining the existing pain (P).

Perspective: This study offers insight into risk factors associated with incidence and progression of chronic pains in young women. We showed certain types of pain such as headaches and back pain present higher severity and persistence, and predicted the incidence of other chronic pains. The clinical implications of these findings relate to the needs for more aggressive intervention in young women developing these types of pain when addressing women's health problems.
\end{abstract}

Keywords: Incidence, progression, race/ethnicity, chronic pain, risk factors

\section{INTRODUCTION}

Our previous studies and others showed that the most common chronic facial pain, the temporomandibular disorders (TMDs) type pain often co-exist with other chronic body pains [1-5] and that the prevalence of these pains changes along life span based on gender and race [1]. In a cross-sectional study of a large biracial community sample of young women we also showed that chronic pains in the head, chest, back, abdomen and face are common [6]. Lifetime back pain prevalence was highest (57\%), followed by headache $(48 \%)$, abdominal $(31 \%)$, chest $(22 \%)$, and facial pain $(17 \%)$. Furthermore, one third of young women had high severity of back pain and headaches, based on intensity, duration, and pain related disability, while for TMDs and chest, the percentages were lower (10-20\%). Caucasians had significantly higher self-reported TMDs-type pain prevalence than African-Americans, but not for the other pains [6]. Therefore, chronic pain not only constitutes an important health problem for young women entering productive adult years, but may also interact, influencing each other. While cross-sectional studies provide information on chronic pain extent, distribution and impact, they only provide information about a single time point, not changes, including incidence and persistence or recovery.

*Address correspondence to this author at the University of California, San Francisco, 707 Parnassus Ave, Box \# 0758, San Francisco, CA 94143-0758, USA; Tel: 1-415-476-5881; Fax: 1-415-476-0858;

E-mail: octavia.plesh@ucsf.edu
Furthermore, the role of different factors such as depression and other socioeconomic factors associated with their progression is harder to establish.

Therefore, longitudinal studies from young population using standardized criteria and validated instrument investigating community populations and examining temporal changes in chronic pain severity, new and recovered rates of these pains may shed new light on the chronic pain progression including the TMDs type pain. Most of the chronic pain studies concern mostly Caucasian populations of higher socioeconomic status [7-13]. Little is known about chronic pain progression in young women of different racial/ethnic and socioeconomic communities and factors associated with incidence, persistence and progression of very common chronic pain.

This is a follow-up study of a large biracial community population of young women of about $50 \%$ African-American and 50\% Caucasian [6] using standardized criteria. The aims of this study are to investigate: 1) the time course (incidence, remission, and progression) of 5 common chronic pains (back, head, face, chest and abdomen), and 2) factors associated with incidence and progression of these types of pain.

\section{METHODS}

\subsection{Design and Sampling Participants}

This is a longitudinal study of a community cohort of young women with up to 5 years of follow-up screened twice for five types of chronic pains. A cohort of young girls was 
recruited in 1987 for the longitudinal, multicenter National Heart, Lung and Blood Institute Growth and Health Study (NGHS) with three centers: California, Ohio, and the District of Columbia to investigate the higher prevalence of cardiovascular disease and obesity risk factors among Black and White females [14]. The California Center recruited 887 girls ages 9-10 (458 black and 429 white) from all public and parochial schools from Richmond Unified School District in west Contra Costa County, California, an area having about equal census tract percentages of Black and White children with the least income and occupational disparity between the races [14]. Household were racially concordant. A very detailed description of the initial recruitment for the NGHS study has been published previously (NHLBI Research Group, 1992, [14]. This study has been approved by the UCSF institutional review board, the Committee on Human Research. The first wave of the pain study joining the existing NGHS investigated only participants from California (west Contra Costa County), while the second wave also included Cincinnati, Ohio. Therefore, this longitudinal report utilizes only the California data. For the first wave, study participants were $19-23$ years old $($ median $=$ 21 ), while for the second wave they were $21-26$ (median $=$ 23).

\subsection{Instruments}

The chronic pain grade (CPG) questionnaire was used for both study waves. CPG has been developed and validated for interview-based research for back, head, face, chest, and abdominal pain in the USA (11) and for cross-sectional [15] and longitudinal studies [16] of both general and patient populations in the UK. This instrument uses identical question sets for five common pain conditions in the prior 6 months: back, head, face, abdomen and chest [11, 12]. Pain had to last for a day or more and to occur several times a year; minor and brief pains were to be excluded. The frequency (once, a few times, $<$ half the days, $>$ half the days, almost every day), daily duration $(<1,1-3,4-8,9-16,17-$ $24 \mathrm{~h})$, average and worst intensity (0-10 scale), interference with daily activity (0-10 scale), and number of days kept from normal activities were recorded for each pain type [12]. Based on these scores, a five-point pain grade was calculated for each pain: 0 (no pain), I (low disability--low intensity), II (-low disability- high intensity), III (high disability, moderately limiting-moderately limiting and IV (high disability-severely limiting). High disability scores (CPG III or IV) reflect important impact on quality of life [12]. Structured telephone interviews were conducted by the NGHS personnel, who established excellent personal report with the cohort members over the study period.

In addition, questions regarding demographics of age, race, educational attainment, and marital status were assessed. Parental income and parental education at the inception of NGHS were also included for these young women.

Participants were divided by first wave responses for each of the 5 pains into those with and without baseline pain. For each of the 5 pains, participants who reported baseline pain were classified as persistent if pain remained at followup or as remitted if pain was absent at follow-up. For each of the 5 pains, participants without baseline pain were classified as incident if pain was present at follow-up.

Predictors for pain persistence (versus remittance) were determined by assessing baseline information. Possible predictive factors included demographics (age, race, education, parental income, marital status), self-rated health (5 levels: poor to excellent), fatigue and sleep problems (prior week), and pain-related items for each type of pain : worst pain intensity in prior week, frequency, duration, severity, from which also the chronic pain grade was established [12]. In addition, psychological data, stress and mood, collected from earlier NGHS waves (i.e. before our 2 waves concerning 5 common pains) were included for present analyses. They . were collected 3 and 5 years prior by our colleagues at the NGHS. Predictors of pain incidence were determined by comparing baseline information between those who remained pain-free with those whose pain started between the 2 assessments. Possible predictors included demographics, psychosocial measures and other pains.

\subsection{Data Analysis}

Incidence and remission rates per 1000 person-years were calculated for each type of pain overall and for each racial group by aggregating the number of cases and amount of follow-up time (time between waves). For each of the 5 pains, high disability (CPG III or IV) at baseline was compared to high disability at follow-up with McNemar's chi-square test. For each of the 5 pains, those without baseline pain were eligible for the incidence analysis, while those with baseline pain were eligible for the remission analysis. Pain remission is the complement of pain persistence so that a factor significantly related to one is significantly related to the other with the same p-value. Proportional hazard regression models of the time until event assessed associations of student status, married/partnered status, education, and Caucasian race with incidence and remission for each of the 5 pains; additional covariates (fatigue, sleep problems, depression, stress, self reported health, as well as either baseline average pain intensity of the other 4 pains or number of the 5 pains in the respondent's lifetime) were assessed in models adjusting for student status, married/partnered status, education, and Caucasian race. Note that hazard ratios for remission are the inverse of hazard ratios for persistence.

\section{RESULTS}

\subsection{Response Rates and Missing Data}

830 women participated at the initial interview and 737 at the follow-up (five who were part of the original NGHS cohort were not part of the initial pain interview). Thus, a total of 732 women participated in both interviews for $88 \%$ retention $(85 \%$ in African-Americans and $91 \%$ in Caucasians). Participants were between 19 and 23 years old at the initial interview. Time between interviews ranged from 1 to 5.2 years, with the mean of 3.1 years and the median 2.9 years (standard deviation of 0.7 and interquartile range of 0.8 years). Thus, participants were between 21 and 26 years old at the follow-up. Racial differences regarding the follow-up response were found with fewer AfricanAmericans responding at the follow-up (Fisher's exact test, $\mathrm{p}=0.014)$. Also, based on parental income, more low income 


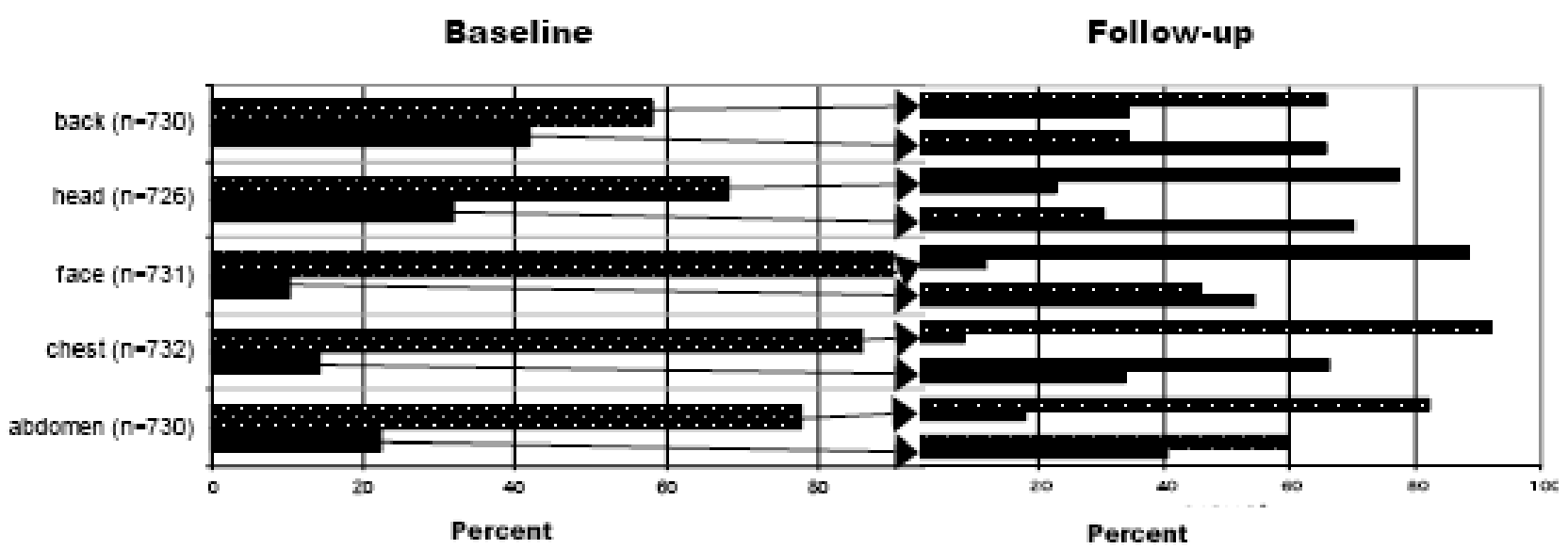

Fig. (1). Six-month period prevalence of five types of pain at baseline pain and at follow-up separately according to baseline pain groupings: pain (solid dark shaded) \& pain-free (dotted light shaded).

individuals were lost at follow-up, partially explaining the racial difference.

\subsection{Prevalence, Persistence, Incidence and Remission}

Fig. (1) graphically displays 6 month prevalences of the five chronic pains at baseline (left) and at follow-up (right). Although, lower than lifetime baseline prevalence, back pain had the highest 6 month prevalence of $42 \%$; at follow-up, $66 \%$ of those with chronic pain at baseline maintained their pain and a lower percent (34\%) remitted. This demonstrated that once developed, back pain largely persists. Of the $58 \%$ back pain-free at baseline, $34 \%$ became new cases and $66 \%$ remained back pain-free at the follow-up visit. Headaches had the next highest 6 month prevalence (31\%); at follow-up $70 \%$ of those with chronic pain at baseline maintained their pain (the highest persistence rate) and a lower percent $(30 \%)$ remitted. Of the $69 \%$ pain-free at baseline, $25 \%$ became new cases and $75 \%$ remained pain-free at the follow-up visit. The least persistent pain was chest pain (34\%), followed by abdominal (40\%) and TMD-type pain (56\%). For TMD-type pain the 6 month pain prevalence was $10 \%$ with $56 \%$ maintaining their pain.

The incidence and remission rates per 1000 person-years are shown overall and by race in Table 1 . Back pain had the highest incidence with a calculated annual rate of $11.3 \%$ and a similar annual remission rate $(11.2 \%)$, followed by headaches with an estimated annual incidence of $7.4 \%$ and annual remission rate of $10.0 \%$. Abdominal pain had the next highest incidence rate $(5.9 \%)$ and $18.8 \%$ remission, followed by face pain with $3.8 \%$ incidence and $15.0 \%$ remission and then chest pain with $2.6 \%$ incidence and $22.2 \%$ remission.

The only significant racial difference was for face pain with Caucasians having higher incidence (relative risk (RR) $=3.27,95 \%$ confidence interval $(\mathrm{CI}): 1.97-5.42, \mathrm{p}<0.001)$ and lower remission $(\mathrm{RR}=0.44,95 \%$ CI: 0.21-0.89, $\mathrm{p}=0.001$ ), which is equivalent to higher persistence ( $R R=2.30,95 \%$ CI: $1.12-4.71, p=0.001)$. The overall face pain incidence rate equates to $3.8 \%$ with $1.8 \%$ in AfricanAmericans and $5.8 \%$ in Caucasians, while remission was
$15.0 \%$ overall with $24.7 \%$ for African-Americans and $10.7 \%$ for Caucasians.

\subsection{Changes in Chronic Pain Severity}

Table 2 presents changes in chronic pain grade (CPG) regarding pain intensity, disability and pain interference with daily life. Those presenting high pain intensity, high disability and moderate to severe limiting at baseline (Grades III and IV) could have improved (remitted) at follow-up (CPG <III) or maintained similar levels of severity (persisted). Those presenting low scores (CPG 0 -II) at baseline could progressively worsen. The highest percentage of those reporting high pain severity at baseline were headaches $(18 \%)$ followed by back $(10 \%)$ and abdominal (7\%) pain. Interestingly, the same severe pains had highest pain persistence (i.e. headaches $42 \%$, back $37 \%$, and abdominal $17 \%$ ) as well as severe pain progression (i.e. headaches $13 \%$, back $8 \%$, and abdominal $5 \%$ ). For other pains (face and chest) most women improved $(100 \%$ and 94\%) at follow-up with a very low percentage worsening at follow-up. Therefore, similar patterns were observed for prevalence, persistence and progression with head, back and abdomen having the highest percentages. However, only chest pain demonstrated statistically significant changes between the two times: more women with severe chest pain at baseline (CPG III-IV) remitted than women with less severe chest pain at baseline (CPG 0 -II) progressed (McNemar's chi-square test, $\mathrm{p}=0.025$ ).

\subsection{Predictors of Incidence and Persistence}

Table 3 presents pain-related factors associated with incidence and remission (the inverse of persistence) for each pain type. Interestingly, some factors are positive predictors of some pains but negative ones with others. For example, being married/partnered was positively related to back pain incidence (hazard ratio $(\mathrm{HR})=1.68,95 \%$ confidence interval (CI): 1.13-2.50) but for headaches, TMDs and abdomen positively associated with pain remission (head, $\mathrm{HR}=1.85$; 95\% CI: 1.06-3.21), (face HR=3.73; 95\% CI:1.40-9.93), (abdomen, HR=1.85; 95\% CI: 1.07-3.19). Therefore, women being married/partnered were 1.68 times more likely to report back pain incidence at follow-up and 3.73 times more 
Table 1. Incidence and Remission Rates Per 1000 Person-Years for Five Types of Baseline Pain in the Prior 6 Months, Overall and by Race.

\begin{tabular}{|c|c|c|c|c|c|c|}
\hline \multirow[t]{2}{*}{ Type } & \multicolumn{3}{|c|}{ Incidence Per 1000} & \multicolumn{3}{|c|}{ Remission Per 1000} \\
\hline & Overall & African-American & Caucasian & Overall & African-American & Caucasian \\
\hline Back & 113 & 112 & 114 & 112 & 117 & 107 \\
\hline Head & 74 & 69 & 77 & 100 & 108 & 92 \\
\hline Face & 38 & 18 & $* 58$ & 150 & 247 & $* 107$ \\
\hline Abdomen & 59 & 55 & 63 & 188 & 193 & 183 \\
\hline Chest & 26 & 25 & 27 & 222 & 238 & 202 \\
\hline
\end{tabular}

${ }^{*} \mathrm{p} \leq 0.05$ comparing African-American to Caucasian.

Table 2. Chronic Pain Grade (CPG) (III-IV) Changes from Baseline to Follow-Up. Remission and Persistence are of those Women with Baseline CPG III-IV while Progression is for those Women with Baseline CPG 0-II. Percent (Count)

\begin{tabular}{|l|c|c|c|c|c|}
\hline Type & Baseline & Follow-up & Follow-up & Follow-up \\
Pemitting & Persisting & McNamara \\
CPG III-IV & CPG III-IV & $\begin{array}{c}\text { Remitting v. } \\
\text { Progressing) }\end{array}$ \\
\hline \hline Back & $10(73)$ & $63(46)$ & $37(27)$ & $8(55)$ & $13(75)$ \\
\hline Head & $18(132)$ & $58(77)$ & $42(55)$ & $1(7)$ & 0.370 \\
\hline Face & $1(8)$ & $100(8)$ & $0(0)$ & $17(9)$ & $5(33)$ \\
\hline Abdomen & $7(53)$ & $83(44)$ & $6(1)$ & $1(5)$ & 0.796 \\
\hline Chest & $2(16)$ & $94(15)$ & & 0.210 \\
\hline
\end{tabular}

Note: those with CPG III-IV at baseline are divided into remitting and persisting at follow-up; those with CPG 0-II at baseline are eligible to progress to CPG III-IV at follow-up.

likely to report baseline face pain remission at follow-up. (Note: being positively predictive of remission is the inverse of being negatively predictive of persistence, so, $\mathrm{HR}=3.73$ for face pain remission is equivalent to $\mathrm{HR}=1 / 3.73=0.27$ for face pain persistence).

Adjusting for student status, marital/partnered status, and education, race was significant only for face pain. Caucasians were 3.19 times more likely than AfricanAmericans to have incident face pain at follow-up $(95 \% \mathrm{CI}$ : 1.85-5.51). Moreover, Caucasians with baseline face pain were less than one-fourth $(\mathrm{HR}=0.23)$ as likely as AfricanAmericans to have pain remission at follow-up $(95 \% \mathrm{CI}$ : 0.09-0.61), which is equivalent to Caucasians with baseline face pain being 4.34 more likely than African-Americans to have pain persist (95\% CI: 1.64-11.1).

Among other factors, fatigue was significantly predictive of incidence for back pain (HR=1.08; 95\% CI: 1.03-1.14), face pain $(\mathrm{HR}=1.09 ; 95 \% \mathrm{CI}: 1.01-1.18)$ and abdomen $(\mathrm{HR}=1.10 ; 95 \%$ CI: $1.03-1.18)$, as well as headaches persistence (negatively with remission, $\mathrm{HR}=0.90 ; 95 \% \mathrm{CI}$ : 0.83-0.98). Reported sleep problems was significantly predictive of persistence for back pain (negatively with remission $\mathrm{HR}=0.94 ; \quad 95 \%$ CI: $0.88-0.99$ ), headaches (negatively with remission $\mathrm{R}=0.91$; 95\% CI: $0.84-0.98$ ) and abdominal pain (negatively with remission, $\mathrm{HR}=0.94 ; 95 \%$
CI: 0.89-0.99). Interestingly, depression was not significantly associated with any pain incidence or persistence/ remission. Stress was predictive of face pain incidence ( $\mathrm{HR}=1.03 ; 95 \% \mathrm{CI}: 1.01-1.06)$ and abdomen pain remission $(\mathrm{HR}=1.03 ; 95 \% \mathrm{CI}$ : 1.01-1.06). Self reported health (i.e. poor health) ) was predictive of back pain incidence $(\mathrm{HR}=1.22 ; 95 \% \mathrm{CI}: 1.05-1.41)$ and face pain incidence ( $\mathrm{HR}=1.33 ; 95 \% \mathrm{CI}: 1.04-1.70)$. No factors were significantly associated with chest pain incidence or remission.

In general, incidence and remission of each pain related to the number of lifetime reported pains (except for chest pain). Therefore, the greater the number of reported pains, the greater the chance to develop other pains and the lower the chance of remission. Having 1 other pain at baseline (versus no baseline pains) significantly related to back $(\mathrm{HR}=1.34 ; 95 \% \mathrm{CI}: 1.14-1.57)$, head $(\mathrm{HR}=1.36 ; 95 \% \mathrm{CI}$ : 1.16-1.51), face (HR=1.29; 95\% CI: 1.05-1.58) and abdomen $(\mathrm{HR}=1.22 ; 95 \% \quad \mathrm{CI}:$ 1.01-1.46) pain incidence and persistence (negatively related to back, $\mathrm{HR}=0.76 ; 95 \%$ CI: $0.62-0.92$ ), head, $\mathrm{HR}=0.71 ; 95 \%$ CI: $0.55-0.91$, face $\mathrm{HR}=0.64$; $95 \%$ CI: $0.43-0.96$, and abdomen $(\mathrm{HR}=0.73 ; 95 \%$ CI: 0.59-0.89).

In addition, back and abdominal pain were significantly inter-related: baseline back pain intensity predicted 
Table 3. Predictors of Pain Incidence Among those Pain-Free at Baseline and of Pain Remission Among those with Pain at Baseline for the 5 Common Pains (Hazard Ratios)

\begin{tabular}{|c|c|c|c|c|c|c|c|c|c|c|}
\hline Predictor & \multicolumn{10}{|c|}{ Pain } \\
\hline Student & 1.18 & 1.06 & 1.12 & 0.44 & 1.73 & 1.49 & 1.21 & 0.85 & 1.24 & 0.75 \\
\hline $\begin{array}{l}\text { Married/ } \\
\text { Partnered }\end{array}$ & 1.68 & 1.14 & 1.46 & 1.85 & 0.70 & 3.73 & 0.70 & 1.85 & 1.20 & 1.33 \\
\hline Education & 1.00 & 0.99 & 0.95 & 1.14 & 1.05 & 1.17 & 0.93 & 0.97 & 0.96 & 1.04 \\
\hline $\begin{array}{c}\text { Caucasian } \\
\text { Race }\end{array}$ & 0.90 & 0.84 & 0.91 & 0.64 & 3.19 & 0.23 & 1.10 & 0.89 & 1.03 & 0.75 \\
\hline Fatigue & 1.08 & 0.97 & 1.04 & 0.90 & 1.09 & 0.99 & 1.10 & 0.96 & 1.09 & 0.96 \\
\hline Stress & 1.02 & 0.99 & 0.98 & 1.01 & 1.03 & 0.99 & 0.99 & 1.03 & 0.99 & 1.01 \\
\hline SR Health & 1.22 & 0.83 & 1.16 & 0.84 & 1.33 & 0.87 & 1.04 & 0.86 & 1.00 & 0.87 \\
\hline \multicolumn{11}{|l|}{$\begin{array}{c}\text { Pain } \\
\text { Intensity }\end{array}$} \\
\hline Back & --- & --- & 1.07 & 1.01 & 1.09 & 1.37 & 1.05 & 0.73 & 1.29 & 1.03 \\
\hline Head & 1.11 & 0.94 & --- & --- & 1.07 & 0.99 & 0.97 & 0.85 & 1.09 & 0.81 \\
\hline Face & 0.60 & 0.58 & 1.72 & 0.91 & --- & --- & 0.62 & 0.52 & 0.82 & 0.74 \\
\hline Abdomen & 1.22 & 1.05 & 1.02 & 1.01 & 1.41 & 1.03 & --- & --- & 0.99 & 0.84 \\
\hline
\end{tabular}

Hazard ratios were adjusted for student status, marital/partnered status, education and race.

$95 \%$ Confidence Intervals excluding 1.0 shown in boldface.

abdominal pain persistence (inversely related to remission at follow-up ( $\mathrm{HR}=0.73 ; 95 \% \mathrm{CI}$ : 0.58-0.91) and baseline abdominal pain intensity predicted back pain incidence at follow-up ( $\mathrm{HR}=1.22 ; 95 \% \mathrm{CI}: 1.03-1.45)$. Baseline face pain intensity is negatively related to both back $(\mathrm{HR}=0.60 ; 95 \%$ CI: $0.39-0.90)$ and abdominal pain ( $\mathrm{HR}=0.62 ; 95 \% \mathrm{CI}: 0.41-$ 0.94 ) incidence and remission (face: $\mathrm{HR}=0.58$; $95 \% \mathrm{CI}$ : 0.39-0.86; abdominal: $\mathrm{HR}=0.52 ; \quad 95 \%$ CI: $0.32-0.84)$; baseline abdominal pain intensity is positively related to face pain incidence $(\mathrm{HR}=1.41 ; 95 \% \mathrm{CI}: 1.12-1.78)$, and baseline back pain intensity is positively related $(\mathrm{HR}=1.37$; $95 \% \mathrm{CI}$ : $1.02-1.82$ ) to face pain remission (negatively related to face pain persistence).

\section{DISCUSSION}

This is one of the first longitudinal studies of a US biracial community population of young women specifically investigating the most common chronic pains and factors predicting their incidence and remission/progression. The results show common chronic pains in these young women, were not only highly prevalent changing their severity over time, showing to be more persistent and severe. Persistence and progression patterns were observed with back, head, and abdominal pain being much greater than face and chest pains similar to those previously reported $[10,12]$. Furthermore, factors predicting incidence versus remission are different shedding new light on pain progression of young women.

This follow-up study had excellent retention (89\%), especially considering participants were at the age with increased mobility from career and family. Time between the first and second interviews was not randomly determined. Older participants at the first interview were more likely lost-to-follow-up partly from relocation outside the area for family or career reasons and perhaps partly from already being harder to reach for the first interview. Participants with lower parental income (disproportionately African-American participants) tended to be lost-to-follow-up more often. However, African-Americans lost-to-follow-up should not have had more face pain incidence than those retained. In fact, since face pain is related to higher SES and lost-tofollow-up is related to lower SES, African-Americans lostto-follow-up might be less likely to have face pain incidence. Thus, the racial difference in facial pain incidence seems robust to loss-to-follow-up. 
Accuracy of incidence reporting (new cases) may be an issue for studies relying on self-reports. Recall bias for a particular time period may exist, especially since respondents may not distinguish initial from subsequent episodes of recurrent pains. It is possible that pains occurred or ceased between the two time periods; for example, respondents who reported persistence may have had a remission between the two time periods and respondents who reported no pain at both times may have had a pain between the two time periods. However, since this cohort was young and questionnaires on lifetime and 6 month period prevalence were validated and structured, recall bias should be minimal and should not be differential between the racial groups.

Back pain prevalence and persistence were similar to previous reports $[17,9]$, demonstrating that back pain develops early in women's lives. Peak headache prevalence was reported as 35-45 years of age [18, 19]. A study of 33,764 twins reported chronic tension-type headaches as significantly more prevalent in women than men, and increasing with age [20]. Our cohort's younger age may explain the lower $(30 \%) 6$ month period prevalence. Since young women have high headache incidence, persistence and severity, increasing with age, points out the need for prevention and treatment targeting young women. Abdominal pain $(41 \%)$ is also common. Most abdominal pain reports concern specific abdominal pains, such as menstrual pain [21] or irritable bowel syndrome [22], which often co-occur, especially in young women [23, 24]. The validated, structured questionnaires in our study concerned general abdominal pain.

Face pain is the only pain of significant racial differences. Compared to African-Americans, Caucasians demonstrated not only higher prevalence but also higher incidence and persistence even after adjusting for SES. Previous facial pain reports mostly from Caucasians with higher SES [25-27], showed chronic facial pain, mostly of temporomandibular origin, is higher in women than men with peak prevalence in young adulthood. Our study, the first investigating a community cohort of African-American and Caucasian young women, shows similar results to previous reports on Caucasians. Also despite methodological differences a longitudinal study on mostly Caucasians adolescents reported similar results regarding incidence and some of the risk factors [28]. Although factors explaining the racial difference are not fully known, our ongoing studies show that age plays a significant role, interacting with race $[29,30]$.

Chest pain, the least prevalent, also had the lowest persistence. Few studies reported on non-specific chronic chest pain and their results were similar to ours (13\%) for similar age women [10]. None of the investigated factors were associated with this type of pain incidence of persistence suggesting a different mechanism involved. Therefore, back, head and to a lesser degree abdominal pains are not only the most common, but also severe and persistent, continuing to affect a significantly higher number of new cases (I).

Several factors were associated with the development of new cases (incidence) and regression or persistence such as demographic, pychosocial and health related factors (Table
3). Some of these factors are uniquely related to the young women's age. Being a student predicted headaches persistence and face pain incidence (Table 3). This is probably related to the life style such as lack of sleep, increased level of fatigue and stress (see below) Marital status (i.e married/ partnered) with the exception of back pain, is related mostly to increased pain remission, again due to lifestyle and perhaps better psychological support. However, with the exception of face pain, at this age, there are no racial differences regarding these pains. However, our recent findings show that minority populations demonstrate an increase in comorbid pains with age compared to Caucasians [30].

Depression is a risk factor consistently reported to be associated with chronic pain [9, 13, 31-33], however, the exact temporal relationship still remains a problem of debate [34]. The complete lack of association in our study may be due to the sequence of data collection. As described in the methods, the data collection on depression preceded our pain data, stress and mood being assessed 2-5 years earlier by our collegues at the NGHS [35]. Therefore, this finding sheds more light regarding not only the chronological relationship (i.e. they may be more closely chronologically associated) but also the cohort' age effect may play a higher role. Poor health was previously reported to relate to chronic pain incidence and persistence, increasing with age $[28,32,36)$. However, with the exception of back and face pain incidence no relationship between poor health and other pains was found. This again, may be the reflection of younger age associated with better health status. Stress predicted the development of facial pain, but not other pains. Association of stress with face pain has been previously reported [24, 33]. Increased fatigue also predicted face, back, and abdominal pain incidence but only headache persistence. This again may reflect on more similarities among the back, abdominal and face pains compared to headaches which as we previously reported [6] develop earlier than the other 4 pains. Sleep problems in young women are only associated with persistence of back, head and abdominal pain suggesting that at young age sleep may be a consequence of pain rather than being a cause [16]. Furthermore, sleep problems are interrelated with the other factors such as stress, fatigue and student status.

The greater number of pain sites, the more likely these young women would develop new and more persistent pains (Table 3). Overwhelming evidence demonstrate increase in number of body pain has been predictive of back pain [9, 31, 37-39], temporomandibular disorder (TMD)-type pain [26$28,40]$, and other types of pain [39-41], having a prognostic value beyond pain duration [33]. The number of chronic pains indicates an increased individual vulnerability to either develop new pain sites (incidence) or maintain pain (persistence). Changes in the nervous system associated with increased lifetime number, level and duration of chronic pains (sensitization) is considered to predispose pain progression [32]. Brain changes, such as decreased thalamic perfusion, are more evident in patients with longer (2-3 years) than shorter (3-7 months) pain duration in brain single photon emission computed tomography (SPECT) images [42]. Peripheral changes, such as elevated cytokines, also differed by pain duration [43]. Therefore, changes in peripheral and/or central nervous system by number of pains 
may explain differences in factors associated with pain incidence and persistence. Furthermore, site-specific relationships among back, face and abdominal pain, excluding headaches, showing that increased baseline intensity in one predisposes incidence or persistence in the others, may reveal insight into shared mechanisms for myofascial type pain. One study reported that individuals with chronic back pain displayed more neuropathic changes such as decreased habituation to multiple stimuli and greater sensitization to painful stimulation compared to tension type headaches [43], chronic pain being also associated with brain changes [44].

\section{CONCLUSION}

Our results demonstrate that a substantial number of young women present common pains such as back, head, abdominal and to a lesser degree facial or chest. Almost half of them continue progressing into severe pains. Increase in number of coexisting pains predict new pains and persistence of the existing ones. Furthermore, the risk factors associated with incidence versus persistence shed new light on the natural history and progression of chronic pain. The clinical significance of these findings strongly suggest that earlier more aggressive treatment of these pains should be provided to minimize more debilitating pain later. Furtheremore, longitudinal studies elucidating the complex relationships of depression, fatigue, and sleep, in the development of new pains and factors involved in creating and maintaining chronic pain must include young women

\section{CONFLICT OF INTEREST}

None declared

\section{ACKNOWLEDGEMENT}

We wish to thank the women in the study for their willingness to participate. This work was supported by US DHHS / NIH / NIDCR grants R03DE012531 and R01DE013487.

\section{REFERENCES}

[1] Plesh O, Adams AS, Gansky SA. Temporomandibular joint and muscle disorder-type pain and comorbid pains in a national US sample. J Orofac Pain 2011; 25: 190-8.

[2] Aaron LA, Burke MM, Buchwald D. Overlapping conditions among patients with chronic fatigue syndrome, fibromyalgia, and temporomandibular disorders. Arch Inter Med 2000; 160: 221-7.

[3] Rhodus NL, Fricton J, Carlson P, Messner R. Oral symptoms associated with fibromyalgia syndrome $\mathrm{J}$ Rheumatol 2003; 30: $1841-5$.

[4] Wiesinger B, MalkerH, Englund E, Wanman A. Back pain in relation to musculoskeletal disorders in the jaw-face: a matched case-control study. Pain 2007; 131: 311-9.

[5] Lim PF, Smith S, Bhalang K, Slade GD, Maixner W. Development of temporomandibular disorders is associated with greater bodily pain experience. Clin J Pain 2010; 26: 116-20.

[6] Plesh O, Crawford PB, Gansky SA. Chronic pain in a biracial population of young women. Pain 2002; 99: 515-23.

[7] Elliott AM, Smith BH, Hannaford PC, Smith WC, Chamber WA. The course of chronic pain in the community: results of a 4-year follow-up study. Pain 2002; 99: 299-307.

[8] Papageorgiou AC, Silliman AJ, MacFarlane GJ. Chronic widespread pain in the population: A seven year follow-up study. Ann Rheum Dis 2004; 61: 1071-4.

[9] Smith BH, Elliott AM, Hannaford PC, Chamber WA, Smith WC. Factors related to the onset and persistence of Chronic back pain in the community: Results from a general population follow-up study. Spine 2004; 29: 1032-40.
[10] Von Korff M, Dworkin SF, LeResche L, Kruger A. An epidemiological comparison of pain complaints. Pain 1988; 32: 173-83.

[11] Von KM, Dworkin SF, LeResche L. Graded chronic pain status: an epidemiologic evaluation. Pain 1990; 40: 279-91.

[12] Von KM, Mormel J, Keefe FJ, Dworkin SF. Grading the severity of chronic pain. Pain 1992; 50: 133-49.

[13] Von Korff M, Le Resche L, Dworkin SF. First onset of common pain symptoms:a prospective study on depression as a risk factor. Pain 1993; 55: 251-8.

[14] National Heart Lung and Blood Institute Growth and Health Study Research Group. Obesity and cardiovascular risk factors in Black and Caucasian girls: The NHLBI Growth and Health Study. Am J Pub Health 1992; 82: 1613-20.

[15] Smith BH, Penny KI, Purves AM, et al. The chronic pain grade questionnaire: validation and reliability in postal research. Pain 1997; 71: 275-9.

[16] Elliott AM, Smith BH, Chamber WA. Changes in chronic pain severity over time: the chronic pain grade as a valid measure. Pain 2000; 88: 303-8.

[17] Crombie IK, Croft PR, LeResche L, Von Korff M, Eds Epidemiology of Pain. Seattle: IASP Press 1999 (Dionne CE: Low back pain, pp. 283-297).

[18] Crombie IK, Croft PR, LeResche L, Von Korff M editors, Epidemiology of Pain. Scher AI, Stewart WF, Lipton R, Eds. Migraine and Headache: A meta-analytic approach. Seattle: IASP Press 1999; pp. 159-70.

[19] Robbins MS, Lipton RB. The epidemiology of primary headache disorders. Semin Neurol 2010; 30: 107-19.

[20] Russell MB, Levi N, Saltyte-Benth J, Ferger K. Tension-type headache in adolescents and adults: A population based study of 33,764 twins. Eur J Epidemiol 2006; 21: 153-60.

[21] Burnett MA, Antao V, Black AV, et al. Prevalence of primary dysmenorrheal in Canada. J Obstet Gynaecol Can 2005; 8: 765-80.

[22] Minocha A, Chad W, Do W, Johnson WD. Racial differences in epidemiology of irritable bowel syndrome alone, un-investigated dyspepsia alone, and "overlap syndrome" among African Americans compared to Caucasians: a population based study. Dig Dis Sci 2006; 51: 218-26.

[23] Altman G, Cain KC, Jarrett M, Burr R, Heitkemper M. Increased symptoms in female IBS patients with dysmenorrheal and PMS. Gastroenterol Nurs 2006; 29: 4-11.

[24] Wilson S, Roberts L, Roalfe A, Bridge P, Singh S. prevalence of irritable bowel syndrome: a community survey. $\mathrm{Br} \mathrm{J}$ Gen Pract 2004; 54: 495-02.

[25] Ohrbach R, Dworkin F. Five-year outcome in TMD: Relationship of changes in pain to changes in physical and psychological variables. Pain 1998; 74: 315-26.

[26] Rammelsberg P, LeResche L, Dworkin SF, Mancl L. Longitudinal outcome of temporomandibular disorders: a 5-year epidemiologic study of muscle disorders defined by Research Diagnostic Criteria for temporomandibular disorders. J Orofacial Pain 2003; 17: 9-20.

[27] Macfarlane TV, Blinkhorn AS, Davies RM, Kincey J, Worthington HV. Oro-facial pain in the community: Prevalence and the associated impact. Community Dent Oral Epidemiol 2002; 30: 5260 .

[28] LeResche L, Mancl LA, Dranghold MT, Huang G, von Korff M. Predictors of onset of facial pain and temporomandibular disorders in early adolescence. Pain 2007; 129: 269-78.

[29] Isong U, Gansky SA, Plesh O. Temporomandibular Joint and Muscle Disorder-type pain in US adults: the National Health Interview Survey. J Orofac Pain 2008; 22: 317-22.

[30] Plesh O, Adams S, Gansky SA. Racial/ethnic and gender prevalences in reported common pains in a national sample. J Orofac Pain 2011; 25: 25-31.

[31] Magni G, Marchetti M, Moreschi C, Merskey H, Luchini SR. Chronic musculoskeletal pain and depressive symptoms in a National Health and Nutrition Examination. Pain 1993; 53: 163-8.

[32] Smith BH, Macfarlane GJ, Torrance N. Epidemiology of chronic pain, from laboratory to the bus stop: time to add understanding of biological mechanisms to the risks factors in population-based research. Pain 2007; 127: 5-10.

[33] Von Korff M, Dunn KM. Chronic pain reconsidered. Pain 2008; 138: $265-76$

[34] Gupta A, Silman AJ, Ray D, et al. The role of psychosocial factors in predicting the onset of chronic widespread pain:results from a 
prospective population-based study. Rheumatology (oxford) 2007; 46: 666-71.

[35] Franco DL, Striegel-Moore RH. The role of body dissatisfaction as a risk factor for depression in adolescent girls Are the differences Black and white? J Psychsomatic Res 2002; 53: 975-83.

[36] Bergman S, Jacobsson LT, Herrstrom P, Petersson IF. Health status as measured by SF-36 reflects changes and predicts outcome in chronic musculoskeletal pain: a 3-year follow up study in general population. Pain 2004; 108: 115-23.

[37] Kuttila M, Niemi PM, Kuttila S, Alamen P, Le Belly. TMD treatment need in relation to age, gender stress and diagnostic subgroups. J Orofac Pain 1998; 12: 67-74.

[38] Kindler LL, Jones KD, Perrin N, Bennet RM. Risc factors predicting the development of widespread pain from back or neck pain. Pain 2010; 22: 1-9.

[39] Forseth KO, Forre O, Gran JT. A 5.5 year prospective study of selfreported musculoskeletal pain and of fibromyalgia in a female population: Significance and natural history. Clin Rheumatol 1999; 18: 114-21.

[40] Gansky SA, Plesh O. Widespread pain and fibromyalgia in a biracial cohort of young women. J Rheumatol 2007; 34: 810-7.

[41] Wanman A, Agerberg G. Recurrent headaches and craniomandibular disorders in adolescents: a longitudinal study. J Craniomandib Disord 1987; 1: 229-36.

[42] Vierck CJ. Mechanisms underlying development of spatially distributed chronic pain (fibromyalgia). Pain 2006; 124: 242-63.

[43] Flor H, Diers M, Birbaumer N. Peripheral and electrocortical responses to painful and non-painful stimulation in chronic pain patients, tension headache patients and healthy controls. Neurosci Lett 2004; 361: 147-50.

[44] Apkarian AV, Bushnell CM, Treede RD, Zubieta JK. Human brain mechanisms of pain perception and regulation in health and disease. Eur J Pain 2005; 9: 463-84.

(C) Plesh et al.; Licensee Bentham Open.

This is an open access article licensed under the terms of the Creative Commons Attribution Non-Commercial License (http://creativecommons.org/licenses/by-nc/3.0/) which permits unrestricted, non-commercial use, distribution and reproduction in any medium, provided the work is properly cited. 